\title{
EHMTI-0032. Persistence and switching characteristics among chronic migraine patient population: a retrospective claims analysis
}

\author{
Z Hepp ${ }^{1 *}$, D Dodick ${ }^{2}$, S Varon ${ }^{1}$, P Gillard', N Mathew ${ }^{3}$, J Chia ${ }^{3}$, R Hansen ${ }^{4}$, EB Devine ${ }^{4}$ \\ From 4th European Headache and Migraine Trust International Congress: EHMTIC 2014 \\ Copenhagen, Denmark. 18-21 September 2014
}

\section{Objective}

Migraine prevention guidelines recommend oral migraine preventive medications (OMPMs) for patients with frequent headache, such as chronic migraine $(\mathrm{CM})$. We sought to understand OMPM treatment patterns by evaluating persistence, medication switching, and medication re-initiation among CM pa

\section{Methods}

A retrospective claims analysis was undertaken using the MarketScan ${ }^{\circledR}$ Databases. The analysis included patients $\geq 18$ years old, with a CM diagnosis, who initiated an OMPM between January 1, 2008 and September 30, 2012. Patient persistence was measured at 6 and 12 months. Time to discontinuation was assessed for each OMPM and compared using Cox regression models. Among those who discontinued, we also assessed the proportion of patients who switched to another OMPM within 60 days or reinitiated treatment with OMPMs between 61 to 365 days.

\section{Conclusion}

Persistence to OMPMs is poor among the US CM population at 6 months and declines further by 12 months. After initial discontinuation, switching or reinitiating is common; however, persistence declines as patients cycle through various OMPMs.

\section{Authors' details}

'Global Health Outcomes Strategy and Research, Allergan Inc., Irvine, USA. ${ }^{2}$ Neurology, Mayo Clinic, Phoenix, USA. ${ }^{3}$ Global Safety and Epidemiology, Allergan Inc., Irvine, USA. ${ }^{4}$ Pharmaceutical Outcomes Research and Policy, University of Washington, Seattle, USA.

Published: 18 September 2014

doi:10.1186/1129-2377-15-S1-G8

Cite this article as: Hepp et al:: EHMTI-0032. Persistence and switching characteristics among chronic migraine patient population: a

retrospective claims analysis. The Journal of Headache and Pain 201415 (Suppl 1):G8.

\section{Results}

A total of 8,707 patients met the inclusion/exclusion criteria. Persistence with the initial OMPM was $25 \%$ at 6 months and $14 \%$ at 12 months. Amitriptyline, nortriptyline, and gabapentin had significantly higher likelihood of discontinuation when compared to topiramate. Of patients who discontinued, approximately $23 \%$ switched to another prophylactic and another $41 \%$ reinitiated therapy within one year. Among patients who switched, 12-month persistence was $13 \%$ to the second prophylactic and $10 \%$ for the third. Among reinitiated patients this rate was $8 \%$ and $4 \%$, respectively.

Submit your manuscript to a SpringerOpen ${ }^{\bullet}$ journal and benefit from:

$\checkmark$ Convenient online submission

- Rigorous peer review

- Immediate publication on acceptance

- Open access: articles freely available online

- High visibility within the field

- Retaining the copyright to your article

Submit your next manuscript at $\gg$ springeropen.com

\section{SpringerOpen ${ }^{\circ}$}

( 2014 Hepp et al; licensee Springer. This is an Open Access article distributed under the terms of the Creative Commons Attribution License (http://creativecommons.org/licenses/by/2.0), which permits unrestricted use, distribution, and reproduction in any medium, provided the original work is properly cited. 